\title{
The Dynamics of Morphogenesis in the Early Mouse Embryo
}

\author{
Jaime A. Rivera-Pérez ${ }^{1}$ and Anna-Katerina Hadjantonakis ${ }^{2}$ \\ ${ }^{1}$ Department of Cell and Developmental Biology, University of Massachusetts Medical School, Worcester, \\ Massachusetts 01655 \\ ${ }^{2}$ Developmental Biology Program, Sloan-Kettering Institute, Memorial Sloan Kettering Cancer Center, New York, \\ New York 10065 \\ Correspondence: hadj@mskcc.org
}

\section{SUMMARY}

Over the past two decades, our understanding of mouse development from implantation to gastrulation has grown exponentially with an upsurge of genetic, molecular, cellular, and morphogenetic information. New discoveries have exalted the role of extraembryonic tissues in orchestrating embryonic patterning and axial specification. At the same time, the identification of unexpected morphogenetic processes occurring during mouse gastrulation has challenged established dogmas and brought new insights into the mechanisms driving germ layer formation. In this article, we summarize the key findings that have reinvigorated the contemporary view of early postimplantation mammalian development.

\section{Outline}

1 Developmental anatomy_From blastocyst to egg cylinder

2 Heterogeneity of egg cylinder tissues

3 The anterior visceral endoderm: Movement, form, and function

4 Shifting the anteroposterior axis: Cause or consequence of gastrulation?
5 The primitive streak: A hub of morphogenetic cellular activity

6 Formation of mesoderm and definitive endoderm

7 Perspectives and concluding remarks

References

Editors: Patrick P.L. Tam, W. James Nelson, and Janet Rossant

Additional Perspectives on Mammalian Development available at www.cshperspectives.org

Copyright (C 2015 Cold Spring Harbor Laboratory Press; all rights reserved; doi: 10.1101/cshperspect.a015867

Cite this article as Cold Spring Harb Perspect Biol 2015;7:a015867 


\section{DEVELOPMENTAL ANATOMY -FROM BLASTOCYST TO EGG CYLINDER}

At the time of implantation, which in the mouse occurs on embryonic day 4.5 (E4.5), the embryo is composed of three distinct cell lineages: epiblast (EPI), trophectoderm (TE), and primitive endoderm (PrE) (Fig. 1; Tables 1 and 2). The trophectoderm and primitive endoderm comprise epithelia of cells that display apicobasal polarity and are held together by adherent and tight junctions. These two epithelia envelop the epiblast in a niche bound by basement membranes composed of laminin, collagen, and fibronectin (Brown 2011).

The TE is subdivided into polar and mural TE. The polar TE abuts the epiblast, and it is fated to form the ectoplacental cone and extraembryonic ectoderm, which will subsequently become part of the placenta. The mural TE initially encloses the blastocoelic cavity and eventually forms the outer layer of the parietal yolk sac. The PrE differentiates into two cell types, the parietal endoderm and the visceral endoderm. Parietal endoderm cells are distributed over the mural trophectoderm cells, eventually forming the endodermal component of the parietal yolk sac. The visceral endoderm possesses the machinery for polarized absorption and transcytosis (Bielinska et al. 1999) and functions as the primary site of gas, nutrient, and waste exchange before the establishment of the maternal-embryonic circulation. The visceral endoderm encapsulates the extraembryonic ectoderm (the extraembryonic visceral endoderm, or exVE) and the epiblast (the embryonic visceral endoderm, or emVE). Collectively, these two cell populations contribute to the endoderm of the visceral yolk sac.

Classic embryological studies noted a period of rapid growth following blastocyst implantation characterized by

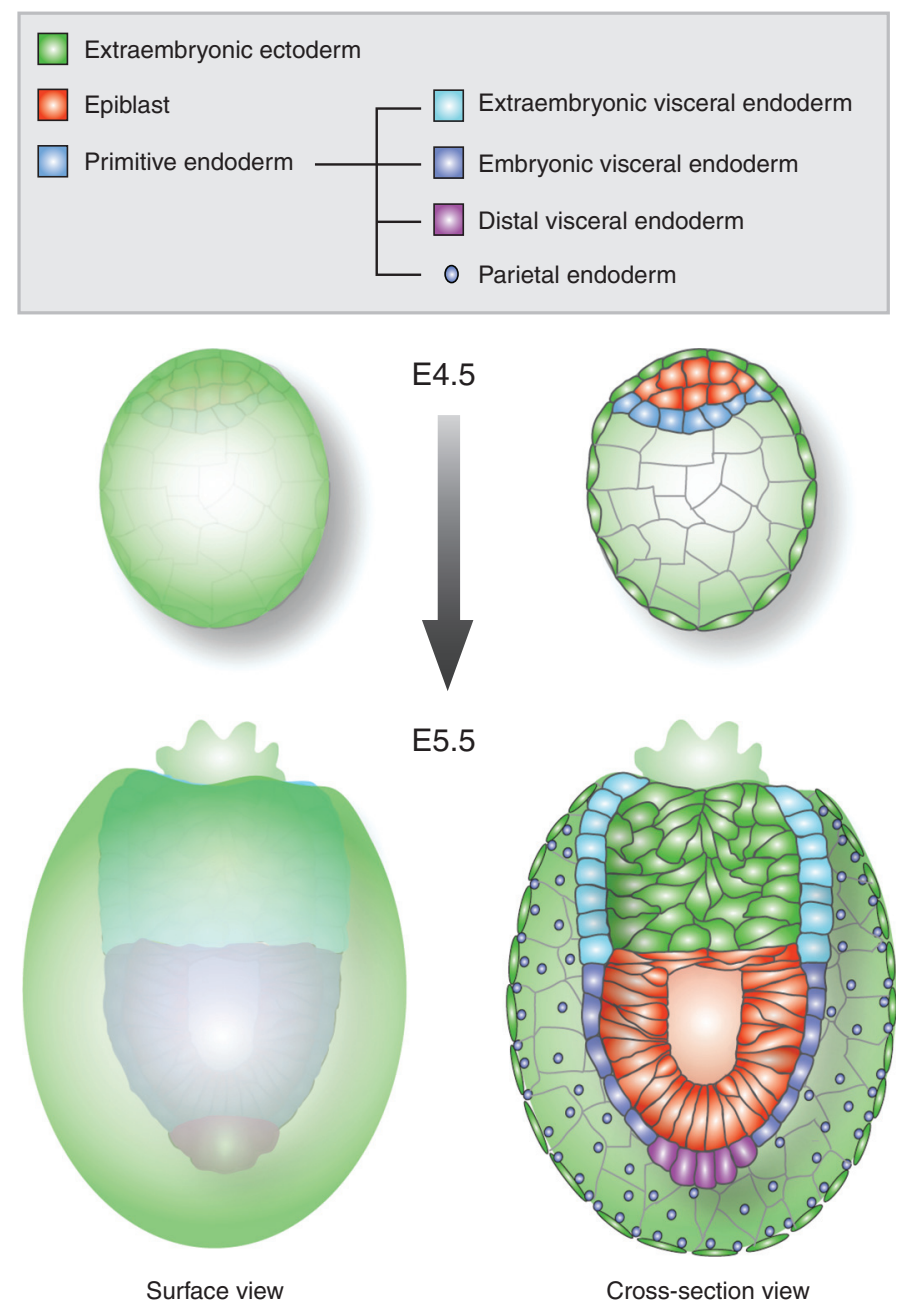

Figure 1. Aposition of tissues in blastocyst and early postimplantation embryo. Schematic representation of implanting blastocyst and early postimplantation embryos revealing the expansion of cell lineages but maintenance of the general spatial relationship in the conceptus. 
Table 1. List of anatomical abbreviations used

\begin{tabular}{ll}
\hline ICM & Inner cell mass \\
EPI & Epiblast \\
PrE & Primitive endoderm \\
TE & Trophectoderm \\
PE & Parietal endoderm \\
VE & Visceral endoderm \\
emVE & Embryonic visceral endoderm \\
exVE & Extraembryonic visceral endoderm \\
DVE & Distal visceral endoderm \\
AVE & Anterior visceral endoderm \\
PVE & Posterior visceral endoderm \\
\hline
\end{tabular}

the expansion of the epiblast into the yolk sac cavity, the space surrounded by the parietal yolk sac (Snell and Stevens 1966; Snow 1977). At E5.5, the epiblast forms a cup-shaped columnar epithelium that surrounds the proamniotic cavity (Fig. 2; Table 3). The formation of the proamniotic cavity is accomplished by cavitation, and concurrently the epiblast grows and is transformed into a pseudostratified epithelium. Differential rates of proliferation as well as uterine mechanical constraints have been proposed to account for shaping the columnar architecture of the extraembryonic ectoderm (Copp 1979) and contributing to the proximodistal elongation of the conceptus.

After the generation of the proamniotic cavity and expansion of the epiblast, the conceptus forms a cylindrical structure with the site of connection to the uterine tissue defining the proximal pole of the proximodistal axis. The cylindrical embryos form at $\sim$ E5.0, when the proamniotic cavity first appears, until $\sim$ E7.5, when the amnion and chorion are fully formed (see Pereira et al. 2011); these are commonly referred to as the "egg cylinder" stages.

The epiblast and extraembryonic ectoderm are two distinct but contiguous epithelia with their apical surface facing the proamniotic cavity (Stephenson et al. 2012). The basal surface of the visceral endoderm that is in contact with both the epiblast and extraembryonic ectoderm is decorated with a basal membrane that was previously laid down between the primitive endoderm and the epiblast of the blastocyst.

\section{HETEROGENEITY OF EGG CYLINDER TISSUES}

\subsection{The Visceral Endoderm Is Morphologically and Molecularly Heterogeneous}

The visceral endoderm can be divided into several subpopulations that are distinguishable by the expression of molecular markers (Perea-Gomez et al. 2007; Pfister et al. 2007; Yamamoto et al. 2009; Trichas et al. 2012). The most conspicuous is a group of cells located at the distal tip of the egg cylinder (distal visceral endoderm, DVE) (Figs. 2 and 3). These cells show increased apicobasal height and rise above their neighboring epithelial cells (Kimura et al. 2000; Rivera-Perez et al. 2003; Srinivas et al. 2004).

DVE cells express a distinctive set of molecular markers, including the transcription factor Hex and antagonists of the Wnt and Nodal signaling pathways including Dkk1, Sfrp1, Sfrp5, Cerl1, and Lefty1 (Pfister et al. 2007). There are currently several fluorescent protein reporter lines that mark DVE cells facilitating their identification in vivo and live imaging (Rodriguez et al. 2001; Mesnard et al. 2004; Takaoka et al. 2011). The DVE will subsequently contribute to part of the anterior visceral endoderm (AVE) (Thomas and Beddington 1996; Rivera-Perez et al. 2003; Srinivas et al. 2004; Takaoka et al. 2011).

A second subpopulation of visceral endoderm overlies the posterior side of the embryo. These posterior visceral endoderm (PVE) cells express Wnt3 (Liu et al. 1999; Rivera-Perez and Magnuson 2005) and Mixl1 (Pearce and Evans 1999; Robb et al. 2000) beginning at E5.5 and continuing until gastrulation. Interestingly, fate mapping and timelapse imaging experiments suggest that these cells do not undergo major rearrangements but generally are cohesive and remain stationary during gastrulation (Lawson and Pedersen 1987; Kwon et al. 2008).

A third subpopulation of visceral endoderm comprises the cells that overlie the extraembryonic ectoderm. These cells are tall columnar in morphology, unlike the squamous visceral endoderm cells overlaying the epiblast but outside the DVE/AVE domain. Several genes are expressed exclusively in these extraembryonic visceral endoderm (exVE) cells at E5.5-E6.5, including Rhox5, also known as Pem (Lin et al. 1994; Chazaud et al. 2006), Sox7 and Sox17 (Kanai-Azuma et al. 2002), and Gata4, among others (Pfister et al. 2007).

A fourth subpopulation within the visceral endoderm overlying the epiblast does not fall into any of these categories. These cells are found on the distal tip of the AVE stage embryo at $\sim$ E5.75. These cells do not express markers of the AVE initially but, like the DVE, they shift anteriorly as the embryo develops. Subsequently, they become part of the AVE and express AVE markers (Rivera-Perez et al. 2003; Takaoka et al. 2011).

\subsection{The Extraembryonic Ectoderm Comprises at Least Two Subpopulations}

Although some genes are expressed widely in the extraembryonic ectoderm (e.g., Rhox/Pem [Lin et al. 1994; Chazaud et al. 2006], Elf [Donnison et al. 2005], and Wnt7b [Kemp et al. 2007]), other genes specifically mark the distal third of 
J.A. Rivera-Pérez and A.-K. Hadjantonakis

Table 2. Definition of cell types and tissues

\begin{tabular}{|c|c|c|}
\hline Trophectoderm & $\mathrm{TE}$ & $\begin{array}{l}\text { One of the three cell lineages of the blastocyst. It is subdivided into the polar trophectoderm, which } \\
\text { lies adjacent to the inner cell mass (ICM), and the mural trophectoderm, which lies adjacent to the } \\
\text { blastocoel cavity. The trophectoderm gives rise to the fetal portion of the placenta and the outer } \\
\text { layer of the parietal yolk sac. }\end{array}$ \\
\hline Inner cell mass & ICM & $\begin{array}{l}\text { A cell population that is internalized in the blastocyst and bounded by the trophectoderm and } \\
\text { blastocoel. The ICM contains the precursors of the epiblast and primitive endoderm lineages. }\end{array}$ \\
\hline Epiblast & EPI & $\begin{array}{l}\text { One of the three cell lineages of the late blastocyst. The epiblast gives rise to almost all of the fetal } \\
\text { tissues and the extraembryonic mesoderm. }\end{array}$ \\
\hline Primitive endoderm & $\operatorname{PrE}$ & $\begin{array}{l}\text { One of the three cell lineages of the late blastocyst: the precursor to parietal endoderm (PE) and } \\
\text { visceral endoderm (VE). }\end{array}$ \\
\hline Parietal endoderm & $\mathrm{PE}$ & $\begin{array}{l}\text { Primitive endoderm-derived cell population that forms by EMT, migrates, and finally lies next to the } \\
\text { mural trophectoderm. Fated to contribute to the inner layer of the parietal yolk sac, as well as the } \\
\text { deposition of the Reichert's membrane. }\end{array}$ \\
\hline Visceral endoderm & VE & $\begin{array}{l}\text { Primitive endoderm-derived epithelial sheet that encapsulates the extraembryonic ectoderm and } \\
\text { epiblast. Fated to form the outer layer of the visceral yolk sac, as well as part of the embryonic } \\
\text { gut tube. }\end{array}$ \\
\hline Distal visceral endoderm & DVE & $\begin{array}{l}\text { A molecularly and morphologically distinct population of visceral endoderm located at the distal tip } \\
\text { of the } \sim \text { E5.5 embryos, containing the precursor of some of the anterior visceral endoderm (AVE). }\end{array}$ \\
\hline Anterior visceral endoderm & AVE & $\begin{array}{l}\text { A population of visceral endoderm that covers approximately half of the epiblast and is located } \\
\text { opposite to the primitive streak or its precursors. }\end{array}$ \\
\hline Posterior visceral endoderm & PVE & $\begin{array}{l}\text { A molecularly distinct population of visceral endoderm overlying the primitive streak or its epiblast } \\
\text { precursors. }\end{array}$ \\
\hline $\begin{array}{l}\text { Extraembryonic visceral } \\
\text { endoderm }\end{array}$ & exVE & $\begin{array}{l}\text { A subset of visceral endoderm cells situated in the extraembryonic region of the conceptus, overlying } \\
\text { the extraembryonic ectoderm. }\end{array}$ \\
\hline $\begin{array}{l}\text { Embryonic visceral } \\
\text { endoderm }\end{array}$ & emVE & $\begin{array}{l}\text { A subset of visceral endoderm cells overlying the epiblast, contributing to the endoderm layer of the } \\
\text { visceral yolk sac as well as part of the embryonic gut. }\end{array}$ \\
\hline Definitive endoderm & $\mathrm{DE}$ & $\begin{array}{l}\text { One of the three germ layers of the early embryo. It gives rise to cells of the epithelial lining of the } \\
\text { respiratory and digestive tracts and precursors of the associated organs, such as the lungs, liver, and } \\
\text { pancreas. }\end{array}$ \\
\hline Gut endoderm & & $\begin{array}{l}\text { Precursor of all endodermal tissues in the adult organism, comprising derivatives of the definitive } \\
\text { endoderm and potentially the embryonic visceral endoderm. }\end{array}$ \\
\hline Mesoderm & & $\begin{array}{l}\text { One of the three germ layers of the early embryo. It gives rise to the musculoskeletal and circulatory } \\
\text { systems and contributes to connective tissues of internal organs. }\end{array}$ \\
\hline Ectoderm & & $\begin{array}{l}\text { One of the three germ layers of the early embryo. It gives rise to the epidermis and the central and } \\
\text { peripheral nervous system. }\end{array}$ \\
\hline
\end{tabular}

the extraembryonic ectoderm. They include Bmp4 (Winnier et al. 1995), Eomes (Arnold et al. 2009), and Brachyury (Perea-Gomez et al. 2004; Rivera-Perez and Magnuson 2005). Morphological studies of the extraembryonic ectoderm suggest that extensive cell rearrangements occur during the remodeling and folding of this tissue marked by a focal enrichment of actin at the apex of folding (PereaGomez et al 2007).

\subsection{The Extraembryonic Ectoderm Is a Source of Signaling Activity}

Several lines of evidence suggest that the extraembryonic ectoderm is the source of signaling molecules that affect the fate of proximal epiblast cells (Fig. 3). Bmp4 mutant embryos display gastrulation defects and fail to generate primordial germ cells (Winnier et al. 1995; Lawson et al. 1999). Because Bmp4 expression in the extraembryonic ectoderm precedes the appearance of primordial germ cells in the epiblast and because this region of the conceptus is adjacent to the region of epiblast giving rise to primordial germ cells, it was proposed that Bmp4 emanating from the extraembryonic ectoderm plays an inducing role in the formation of primordial germ cells. Chimera experiments further showed that Bmp4 is necessary for the generation of primordial germ cells (Lawson et al. 1999). In vitro experiments have also shown that $\mathrm{Bmp} 4$ can promote the formation of primordial germ cells, suggesting that Bmp4 may act as an inducer (de Sousa Lopes et al. 2004; Ohinata et al. 2009). Another BMP molecule expressed in the extraembryonic ectoderm, $B m p 8 b$, has also been implicated in the signaling events for the specification of the primordial germ cells (Ohinata et al. 2009). Nonetheless, at present, there is no experimental evidence to suggest that ectopic expression of these molecules can lead to the ectopic formation of primordial germ cells in vivo. 


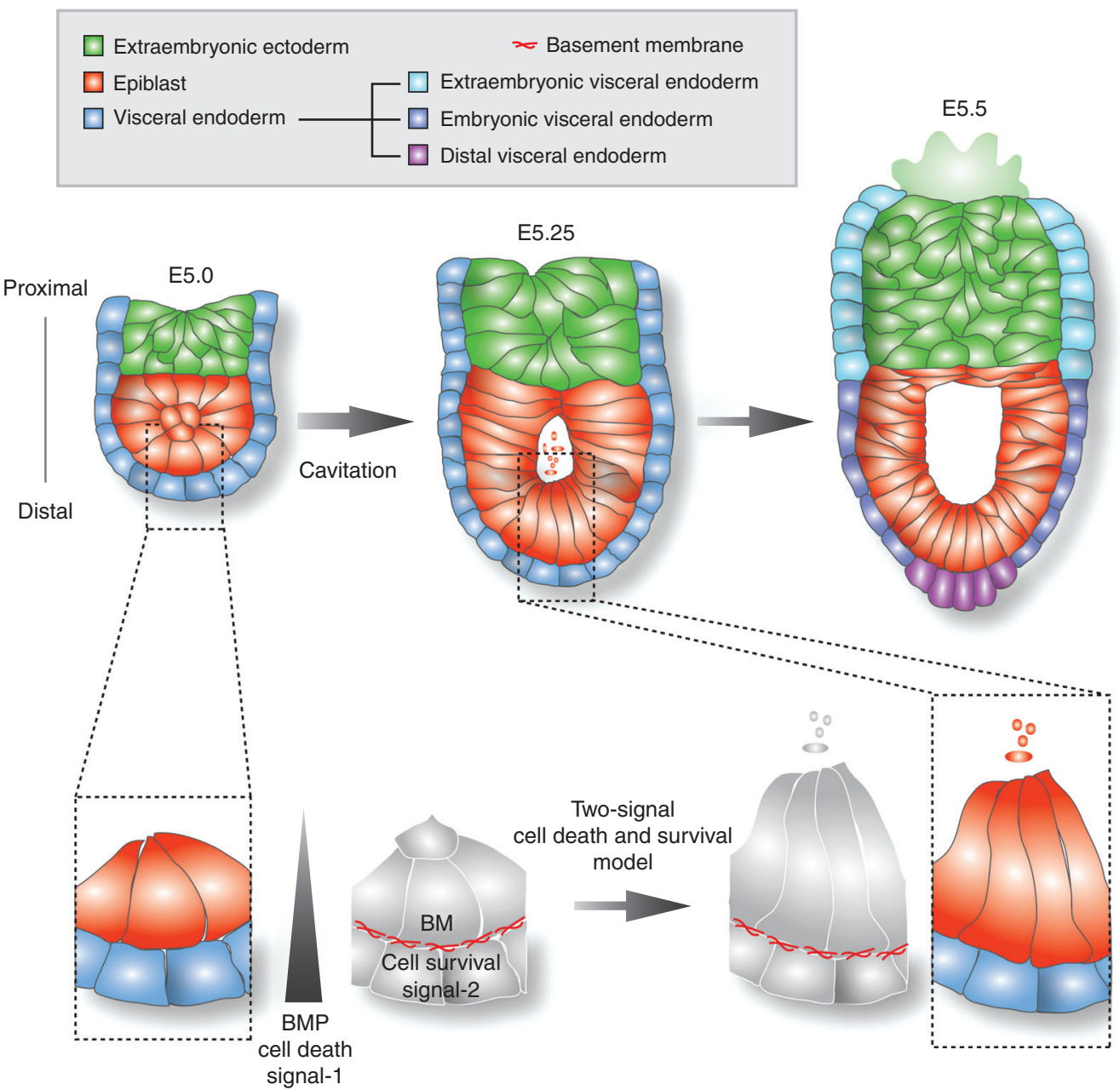

Figure 2. Cavitation of the epiblast at early postimplantation. Schematic representation of the transformation of the mouse egg cylinder from a solid mass to a hollow cup-shaped structure. Studies primarily using embryoid bodies (EBs) as in vitro models, complemented with the analysis of mouse embryos, have led to a cavitation model that involves an interplay of two signals_-one promoting cell death and one cell survival (Coucouvanis and Martin 1995). The first (a death signal) is produced by, or dependent on, the adjacent layer of visceral endoderm cells. This signal is believed to act over short distances to create a cavity by inducing the apoptosis of epiblast cells that are internal, positioned at a distance from the visceral endoderm. The second (a survival signal) is mediated through contact with the basement membrane (BM) positioned at the epiblast/visceral endoderm interface. This second signal has been proposed to promote the survival of epiblast cells located adjacent to the visceral endoderm, which will come to line the resulting cavity. Subsequent studies have suggested a role for Bmp signaling in triggering the apoptosis taking place within the epiblast (Coucouvanis and Martin 1999).

Further evidence for a signaling role of the extraembryonic ectoderm comes from studies on the Nodal signaling pathway (Ang and Constam 2004). The extraembryonic ectoderm is the source of the proteases Spc1 (Furin) and Spc4 (Pace4) (Beck et al. 2002), which cleave the Nodal preprotein to create functional Nodal. Mutations of both genes abrogate the production of active Nodal in the epiblast, leading to arrested gastrulation. A feedback loop has been proposed whereby Nodal signals to the extraembryonic ectoderm to activate Bmp4 expression, then Bmp4 signals back to the epiblast to activate primitive streak markers such as Wnt3 (Ben-Haim et al. 2006). Recently, an imaging-based strategy called CLIP (cell-surface-linked indicator of proteolysis) was used to monitor the action of Furin and PACE in situ in embryos (Mesnard and Constam 2010). This ingenious approach uses FRET (Förster resonance energy transfer) and a proprotein convertase reporter composed of two spectrally distinct (YFP and CFP) fluorescent proteins linked by a proprotein convertase recognition motif. In this way, Furin and PACE-dependent motif cleavage can be imaged in vivo in embryos. Even though the initial study only analyzed fixed tissue samples, it is only a matter 
Downloaded from http://cshperspectives.cshlp.org/ on April 26, 2023 - Published by Cold Spring Harbor Laboratory Press J.A. Rivera-Pérez and A.-K. Hadjantonakis

Table 3. Definition of cell morphologies and morphogenetic cell behaviors

Epithelium

Mesenchyme

Epithelial-to-mesenchymal transition (EMT)

Mesenchymal-to-epithelial transition (MET)

Intercalation

Ingression

Egression
A laterally coherent sheet of cells with distinct apical-basal polarity.

Cells or aggregates lacking the criteria for epithelia are defined as mesenchymal. Although mesenchymal cells are sometimes polarized, the orientation of their polarization is generally random.

Conversion of an epithelial cell to a mesenchymal cell. This requires changes in morphology, cellular architecture, adhesion, and migration capacity.

Conversion of a mesenchymal cell to an epithelial cell. This also requires changes in morphology, cellular architecture, adhesion, and migration capacity.

The insertion of individual cells between other cells. This process is observed in both mesenchyme and epithelia.

A process by which cells exit from an epithelium.

A process by which mesenchymal cells are incorporated into an epithelium, often resulting in the expansion of the epithelium. Egression is, in principle, one form of intercalation.
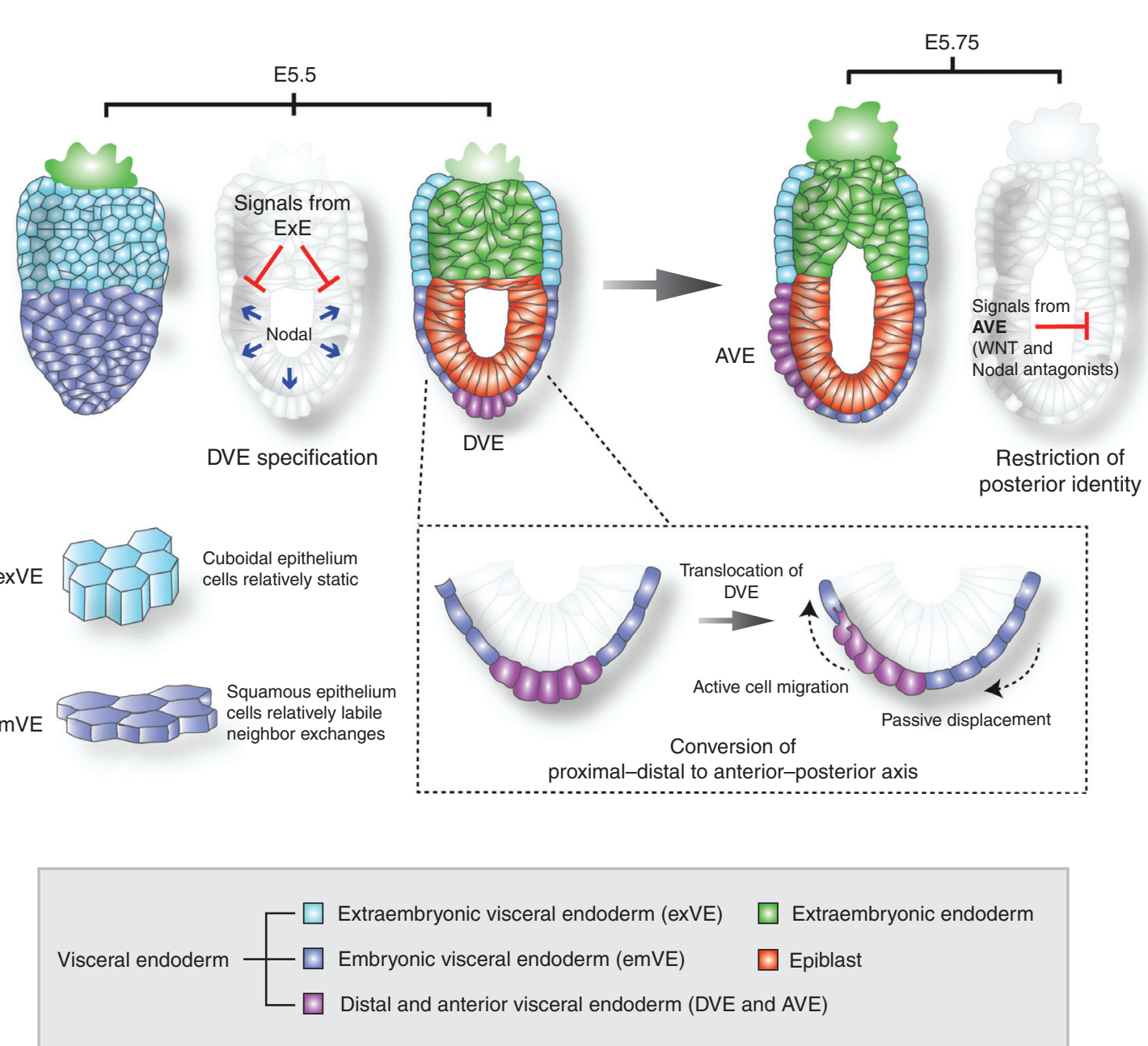

Figure 3. Differential cell populations and behaviors within the visceral endoderm. Depiction of the different cell populations comprising the visceral endoderm as defined by both position and morphology, as well as the key events of tissue displacement and the signaling activity taking place between E5.5 and E5.75. 
of time until this or a comparable live imaging approach is used to monitor signaling dynamics in living embryos.

\section{THE ANTERIOR VISCERAL ENDODERM: MOVEMENT, FORM, AND FUNCTION}

The anterior visceral endoderm (AVE) is found in the anterior region of the embryo opposite to the primitive streak (Fig. 3). The AVE was first recognized as a distinct visceral endoderm subpopulation marked by an antibody, VE-1, that recognizes an unknown epitope (Rosenquist and Martin 1995). Since its discovery, it has also been established that the AVE is related by lineage and shows similarities with the DVE in that its cellular composition changes as the embryo develops, and that it plays a critical role in embryo patterning.

\subsection{The AVE Is a Dynamic Structure with Multiple Precursors}

The progression from DVE to AVE has been traced morphologically (Fig. 3). As embryonic development proceeds, DVE cells shift to a laterodistal position and eventually reach the boundary between the epiblast and extraembryonic ectoderm (Rivera-Perez et al. 2003). The translocation of the DVE is considered an indication of the acquisition of anteroposterior polarity of the mouse embryo. By E6.5, the AVE is evident in the proximal-anterior position adjacent to the cranial endodermal furrow. Multiple genes encoding transcription factors or secreted molecules are expressed in the DVE/AVE (Pfister et al. 2007). The DVE/AVE can be visualized in vivo in transgenic embryos that carry fluorescent reporters under the control of DVE/AVE-specific regulatory elements such as the Hex-GFP, Cerl-GFP, or LeftymVenus mice (Rodriguez et al. 2001; Mesnard et al. 2004; Takaoka et al. 2011).

The AVE is not a static or homogeneous structure. Clonal analyses have shown that at E5.75, the AVE is predominantly composed of Hex-expressing DVE cell descendants (Rivera-Perez et al. 2003; Srinivas et al. 2004), but $12 \mathrm{~h}$ later $(\sim \mathrm{E} 6.25)$ they are joined by cells recruited from non-Hex-expressing cells located previously at the distal tip of the embryo (Rivera-Perez et al. 2003; Takaoka et al. 2011). The AVE of the early streak embryo ( E6.5) therefore contains descendants of DVE cells forming an arc over the anterior region of the embryo and non-DVE cells located between the area demarcated by the DVE descendants. Although it is true that the AVE resides over anterior structures of the embryo, this is the case only in mid- to latestreak stage embryos, when it overlays the anterior neurectoderm (Lawson and Pedersen 1992). At earlier stages, the AVE abuts the precursors of extraembryonic mesoderm that contribute to the amnion, chorion, and visceral yolk sac.

\subsection{Mechanisms Controlling the Translocation of the DVE/AVE}

The mechanisms driving the cellular rearrangement accompanying the shift in the position of the DVE/AVE are not entirely clear. The epithelial integrity of the visceral endoderm is maintained during this event, and questions remain regarding whether this shift in position is an active or a passive event. A passive displacement of DVE cells driven by localized cell proliferation within the visceral endoderm epithelium has been proposed (Yamamoto et al. 2004). However, this is unlikely to be the mechanism driving AVE formation because the transition from DVE to AVE occurs rapidly within $\sim 5-7 \mathrm{~h}$ (Rivera-Perez et al. 2003; Srinivas et al. 2004), and the rate of cell proliferation, with a cell cycle time of $\sim 10 \mathrm{~h}$ (Stuckey et al. 2011), may not be sufficient to account for the relocation of this cellular population. There is also no evidence of synchronized cell division that would provide a burst of localized cell proliferation that could, in principle, propel this directional tissue movement.

To date, live imaging, cellular morphology, and genetic evidence provide the strongest argument that the mechanism driving the transformation of DVE/AVE is cell migration. Time-lapse imaging experiments have revealed that cells extend oriented filopodial projections, suggesting an anterior direction of movement (Srinivas et al. 2004). Moreover, projections are extended basally as cells move forward, suggesting that cells at the leading edge might probe a path that the rest of the population will follow. The extension of filopodia has been interpreted as evidence of cell movement toward a chemoattractant (Srinivas et al. 2004) or away from a chemorepellant (Kimura-Yoshida et al. 2005). While a role of filopodia in cell migration is well established, filopodia can also function as sensors that allow a cell to sample its environment, or they can play a role in other processes such as cell adhesion (Mattila and Lappalainen 2008). Therefore, caution should be taken in inferring a link between filopodial activity and AVE cell movement before more direct evidence is available. An alternative possibility is that DVE cells might migrate in response to cues from the underlying basement membrane (Rodriguez et al. 2005; Salgueiro et al. 2006). Various planar cell polarity (PCP) proteins are expressed in the DVE/AVE (Crompton et al. 2007), suggesting that DVE/AVE cells might move through planar polarity-dependent cellular rearrangement within the visceral endoderm epithelium.

Evidence for active cell movement driving the translocation of the DVE has been provided by the analysis of 
mutations in cytoskeletal machinery components. Nap1, a component of the WAVE complex, has been shown to be important for the translocation of the DVE/AVE (Rakeman and Anderson 2006). The WAVE complex is essential for the migration of many cell types because it promotes the formation of branched actin networks at the leading edge of migrating cells (Davidson and Insall 2011). An additional component of the cell migration machinery that has been implicated in this process is the GTPase Rac1. Rac1 acts downstream from the WAVE complex and is activated by microtubule growth, where it functions to promote actin polymerization in lamellipodia, matrix adhesion, and cell survival. A study in which Racl was specifically ablated in the visceral endoderm revealed its requirement for the repositioning of the DVE (Migeotte et al. 2010). There are, however, caveats to the interpretation of these loss-of-function experiments; first, these components may function not only in cell migration, but also in the maintenance of cell morphology and epithelial integrity, or in controlling the cell cycle. Moreover, Nap1 and Rac1 mutations inactivate multiple cell types in the embryo, not just components of the DVE/AVE, likely affecting cellular behavior in a global manner.

DVE cells exchange neighbors as they become AVE, but cell mixing is always restricted to the embryonic visceral endoderm (emVE) (Trichas et al. 2011). Indeed, lineagetracing experiments have revealed that extraembryonic visceral endoderm cells show coherent growth that limits cellular mixing, unlike the cells of the embryonic visceral endoderm (Lawson and Pedersen 1987; Weber et al. 1999; Perea-Gomez et al. 2007). Time-lapse data reveal that cells consistently halt at the boundary between the epiblast and extraembryonic ectoderm (Srinivas et al. 2004). It has been suggested that the limits of DVE/AVE migration are determined by regional differences in cell behavior and protein localization (Trichas et al. 2011). Indeed, lineage-tracing experiments have revealed that extraembryonic visceral endoderm cells have coherent growth that limits cellular mixing, unlike the cells of the embryonic visceral endoderm (Lawson and Pedersen 1987; Weber et al. 1999; Perea-Gomez et al. 2007). Recent work suggests that the intersection of the Nodal and PCP pathways defines regions of differing cellular behavior within the visceral endoderm epithelium, and in doing so, may promote the collective cell migration or the reorganization of cells within the visceral endoderm epithelium (Trichas et al. 2011).

Analysis and mathematical modeling of visceral endoderm cell behaviors in living embryos have revealed some unexpected cell population dynamics that include the formation of multicellular rosettes as well as local neighbor exchange (Trichas et al. 2012). Multicellular rosettes comprising more than five cells meeting at an apex are a PCP- dependent activity that has been proposed to buffer the disequilibrium in cell packing generated within an epithelium to maintain epithelial integrity and facilitate planar cell relocation.

Although the prevailing view favors an active collective cell migration as the predominant mechanism driving the movement of DVE/AVE cells, evidence supporting an actual movement of this population relative to a fixed point is currently lacking. Beyond the visualization of leadingedge protrusions, no further hallmarks of the signature sequence of cellular behaviors that characterize migrating cells have been reported (for review, see Raftopoulou and Hall 2004; Gardel et al. 2009). These include evidence for the establishment of new adhesion sites at the leading edge of the cell, cell body contraction, and detachment of adhesions at the trailing edge. Such observations are difficult to gather in vivo given the size and shape of the mouse embryo and are further complicated by the fact that multiple cellular rearrangements in two adjacent epithelia coupled with proliferation are occurring simultaneously.

Events occurring in the epiblast, which proliferates at a faster rate than the visceral endoderm (Snow 1977; Stuckey et al. 2011), may also influence the movement and ultimately the location of adjacent DVE cells. In Cripto mutant embryos, for example, the DVE remains at the distal tip of the epiblast, and Cripto is not expressed in the visceral endoderm layer. Cell shape changes in the visceral endoderm or epiblast could also, in principle, produce a global shape change within the egg cylinder that could result in repositioning of the DVE/AVE without the need for cell proliferation or migration. Clearly, more detailed analyses are required before definitively attributing a role for active cell migration in the generation of the AVE. These would involve analysis of all visceral endoderm cell populations in unison, rather than individually in isolation.

\subsection{The AVE as a Signaling Source}

Embryos that lack Cerl1 and Lefty1, two signaling molecules expressed in the AVE, show ectopic primitive streak formation that can be rescued by the ablation of one copy of Nodal (Perea-Gomez et al. 2002). Thus, the AVE serves as the source of secreted molecules that antagonize Nodal and repress the formation of the primitive streak. There is also evidence that the AVE antagonizes Wnt signaling from mutants in which the DVE fails to translocate and remains over the distal tip of the epiblast. These include Cripto, Otx2, and Lpp3 mutant embryos (Ding et al. 1998; Zakin et al. 2000; Perea-Gomez et al. 2001; Escalante-Alcalde et al. 2003). In these mutants, markers of the primitive streak are ectopically expressed in cells located opposite to the primitive streak, where they are not normally expressed. Otx2 and 
Lpp3 mutants also show radialization of Wnt3, a gene essential for primitive streak formation. In vitro experiments suggest that the antagonistic action of the AVE to Wnt signaling can occur via Sfrps and Dkk1, two secreted proteins expressed in the AVE. Sfrps (secreted frizzled-related proteins) physically bind Wnt molecules, and Dkk1 can block Wnt signaling by binding to LRP receptors (Kawano and Kypta 2003). Taken together, these data suggest that the primary role of the AVE is to restrict the activity of factors such as Nodal and Wnt to the posterior of the embryo.

Recently, Bmp2 signaling emanating from the AVE has been linked to the morphogenesis of the foregut and positioning of the head and heart (Madabhushi and Lacy 2011), suggesting a subsequent signaling role of the AVE at gastrula stages.

\subsection{Specification of the DVE/AVE}

The current view of how the DVE/AVE is specified, based primarily on genetic evidence, suggests that Nodal signaling is required for the formation of this specialized visceral endoderm subpopulation ( $\mathrm{Lu}$ and Robertson 2004; Arnold and Robertson 2009; Yamamoto et al.2009). Further evidence suggests that signals emanating from the extraembryonic ectoderm function to provide regional restriction and prevent the ectopic expression of DVE/AVE markers throughout the visceral endoderm (Rodriguez et al. 2005; Georgiades and Rossant 2006; Richardson et al. 2006). An additional regulator is the Wnt signaling pathway, since $A p c$ and $\beta$-catenin mutant embryos show DVE specification defects (Huelsken et al. 2000; Chazaud and Rossant 2006).

Labeling of single inner cell mass cells at E3.5 has revealed the polyclonal origin for the DVE (Perea-Gomez et al. 2007), and genetic fate mapping experiments conducted at E4.5 suggest that the DVE may be specified earlier than initially thought (Takaoka et al. 2011). These experiments suggest that the DVE arises from precursors resident within the primitive endoderm of the implanting (E4.5) blastocyst (Takaoka et al. 2011). However, these precursors are not strictly committed to a DVE fate but also give rise to non-DVE descendants within the visceral endoderm (Takaoka et al. 2011).

\section{SHIFTING THE ANTEROPOSTERIOR AXIS: CAUSE OR CONSEQUENCE OF GASTRULATION?}

Seminal histological studies revealed that the egg cylinder and the proamniotic cavity, in particular, show a flattened ellipsoid shape in a transverse section plane, raising the possibility of a morphological link to the anteroposterior axis of the embryo (Snell and Stevens 1966). Further studies of E5.75 embryos, in which the AVE is recognizable, confirmed these observations. The AVE is located on one side of the shorter axis of the cross section of the cylinder opposite from the site of primitive streak formation ( $\mathrm{Ri}$ vera-Perez et al. 2003). Based on the position of the AVE, the egg cylinder, therefore, appears flattened in the prospective anteroposterior dimension. After the formation of the primitive streak, embryos retain their flattened cylindrical shape; however, by this stage, the AVE is positioned diametrically opposite to the primitive streak across the long axis in the cross-sectional plane of the embryo (Fig. 4). This transformation of embryo shape is achieved by tissue remodeling rather than cellular rearrangement brought about by cell migration (Mesnard et al. 2004; Perea-Gomez et al. 2004), and is dependent on Wnt3 and Fgf8 activity (Barrow et al. 2007; Guo and Li 2007).

The geometric change of the anteroposterior axis precedes the appearance of the primitive streak (Mesnard et al. 2004; Perea-Gomez et al. 2004) and coincides with the onset of expression of primitive streak markers in the posterior epiblast at E6.0 (Rivera-Perez and Magnuson 2005). Whether these morphogenetic changes might reflect physical constraints exerted by the DVE/AVE that restrict epiblast growth to the posterior tissues of the embryo is not known. However, in mutants in which the DVE remains stationary, the expression of primitive streak markers and the egg cylinder does not show any asymmetry that may predict the alignment of the embryonic axis (Ding et al. 1998; Perea-Gomez et al. 2001). This form-shaping process in the egg cylinder may serve to distance the primitive streak precursors from inhibitory signals emanating from the AVE (Perea-Gomez et al. 2004). However, this change in the geometry of the egg cylinder is not a prerequisite of primitive streak formation or gastrulation, because $F g f 8$ mutants that fail to undergo such change in embryo shape can still initiate gastrulation (Barrow et al. 2007; Guo and Li 2007).

\section{THE PRIMITIVE STREAK: A HUB OF MORPHOGENETIC CELLULAR ACTIVITY}

The onset of gastrulation is heralded by the formation of the primitive streak, a region of the epiblast where cells undergo an epithelial-to-mesenchymal transition (EMT). The primitive streak first appears within the proximal epiblast underlying the posterior visceral endoderm at the extraembryonic/embryonic boundary. The position of the primitive streak defines the posterior pole of the embryo, marks a conduit for the production of mesoderm and endoderm cells, and can be regarded as a posteriorly positioned growth zone. 


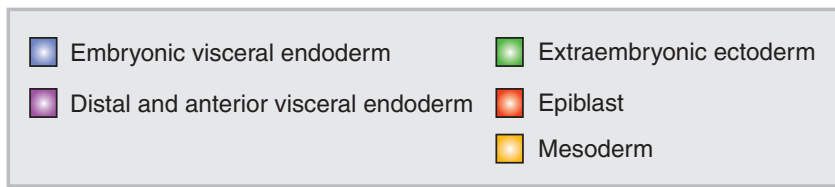

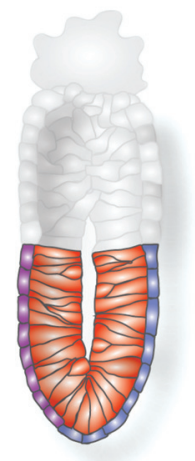

E6.0 prestreak

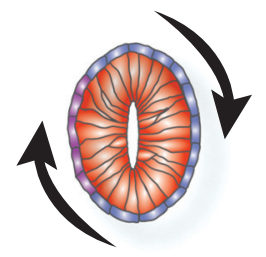

Initiation of gastrulation
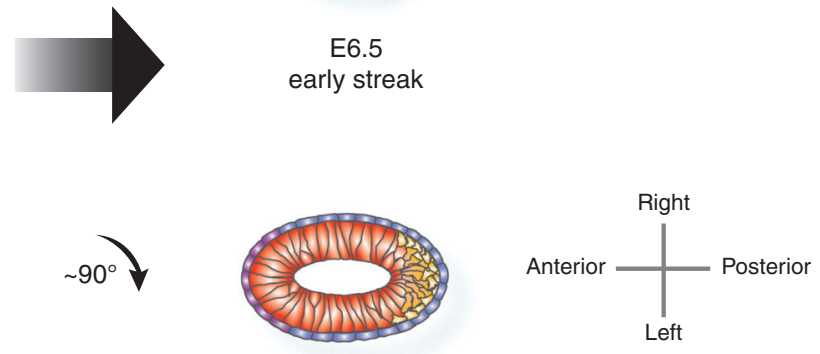

Long axis of ellipse becomes alligned with anterior-posterior axis

Figure 4. Remodeling of the conceptus concomitant with the onset of gastrulation. Schematic representation of the reshaping of the egg cylinder resulting in the alignment of the prospective anterior-posterior embryonic axis to first the short axis and then the long axis of the ellipsoidal cross section of the egg cylinder.

\subsection{Signals that Specify the Primitive Streak}

At $\sim$ E6.5, the primitive streak appears as a local morphological discontinuity in the posterior epiblast epithelium (Figs. 4 and 5). However, the detection of molecular markers of the primitive streak at E5.75 may suggest that the onset of gastrulation occurs $\sim 1 \mathrm{~d}$ before the overt formation of the primitive streak at E6.5.

Several molecular markers pinpoint the prospective location of the primitive streak in the embryo. The earliest is Wnt3 expression in the posterior visceral endoderm of E5.5 embryos (Rivera-Perez and Magnuson 2005; Torteloe et al. 2013). At E5.75, Wnt3 is expressed in the epiblast adjacent to the extraembryonic ectoderm and opposite to the location of the AVE. By E6.0, the T-box transcription factor Brachyury can be detected in the same region of the epiblast as $W n t 3$. There are also reports of activation of the canonical Wnt/ $\beta$-catenin signaling pathway in the same region and at the same developmental stage as
Brachyury (Maretto et al. 2003; Mohamed et al. 2004). Genetic studies have pointed to two key signaling molecules-Nodal (Arnold and Robertson 2009) and Wnt3 (Liu et al. 1999; Rivera-Perez and Magnuson 2005; Tortelote et al. 2013) - that play important roles in the induction of the primitive streak.

\subsection{Germ Layer Formation Involves the Generation of Three Tissue Layers and Two Basement Membranes}

At the primitive streak, cells undertake a sequence of events as they ingress toward the basal side of the epiblast and transit from an epithelial to a mesenchymal state, which facilitates their migration and invasion into the space between the visceral endoderm and epiblast (Fig. 5). Cells executing the program of ingression and epithelial-mesenchymal transition (EM) migrate as coherent mesenchymal cell sheets away from the primitive streak and 


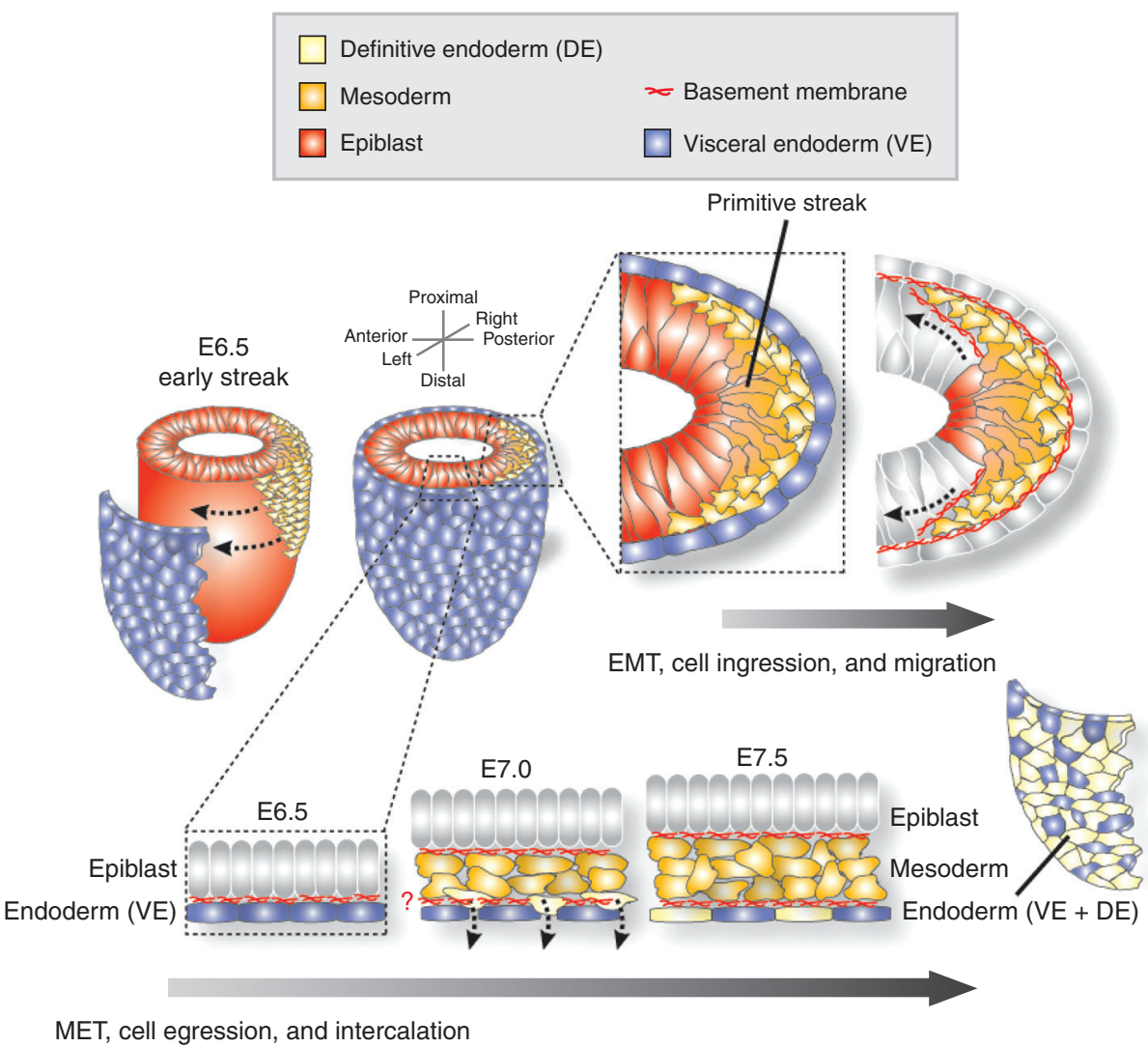

Figure 5. Gastrulation: morphogenesis of mesoderm and endoderm. Depiction of the morphogenetic cellular behavior accompanying germ layer formation. At the primitive streak, cells undergo EMT, ingress, and migrate away to form the mesoderm. Cells fated to form the definitive endoderm undergo MET and egress into the epithelium of the embryonic visceral endoderm.

form the bilateral wings of mesoderm of the egg cylinder. The mesoderm migrates in a posterior-to-anterior direction and eventually forms a complete layer of tissue sandwiched between the epiblast and the endoderm. This leads to the separation of the previously apposed epithelial tissues by an intervening mesenchymal layer (Fig. 5). This also necessitates the formation of an additional layer of basement membrane either at the epiblast/mesoderm or the mesoderm/endoderm interfaces.

\subsection{Cell Behaviors Driving Primitive Streak Formation}

Little is known regarding the epiblast cell behaviors preceding primitive streak formation in the mouse. In the chick, Polonaise movements involving the large-scale rotational movement of cells serve to position the precursors of the primitive streak in the posterior region of the embryo (Voiculescu et al. 2007). In mice, clonal analysis of single cells has shown an anisotropic spread of epiblast cells at stages just before the appearance of the primitive streak
(Lawson et al. 1991). A similar posterior spreading of proximoanterior epiblast cells was observed in embryos labeled at $\mathrm{E} 5.75, \sim 1 \mathrm{~d}$ before the appearance of the primitive streak (Rivera-Perez and Magnuson 2005). Recent live imaging studies, however, argue that the formation of the primitive streak does not require large-scale movements of cells (Williams et al. 2012). Instead, the primitive streak is thought to form in situ by progressive initiation of EMT in posterior epiblast cells.

The formation of the primitive streak has been proposed to occur in three sequential steps: loss or remodeling of the basement membrane at the epiblast/visceral endoderm interface, cell ingression, and streak elongation (Williams et al. 2012). As is characteristic for epithelia, cells of the epiblast show apicobasal polarity and are closely apposed to a basement membrane composed of fibronectin, laminin, and collagen (Brown 2011). Presumably concomitant with primitive streak formation, epiblast cells must remodel or break down the basement membrane at the epiblast/visceral endoderm interface, which acts as a barrier to their ingression, EMT, and subsequent movement 
away from the streak (Fig. 5). To do so, cells must downregulate the expression of genes encoding extracellular matrix (ECM) components and/or degrade basement membrane proteins to create a conduit for their transition and ingression. In the chick, the breakdown of basement membrane is mediated through the relocalization of RhoA, a small GTPase (Nakaya et al. 2008). RhoA activation is lost basally as cells ingress through the primitive streak, leading to degradation of the basement membrane.

Degradation of the basement membrane is followed by cell ingression into the primitive streak. Cell ingression is thought to occur by constriction of epiblast cells at their apical surface facing the proamniotic cavity, followed by soma translocation to allow ingression into the primitive streak (Williams et al. 2012). Several signaling pathways, including Fgf and Wnt, are required for cell ingression and EMT at the primitive streak. Mutants in components of the Fgf signaling pathway including fibroblast growth factor 8 (Fgf8) and Fgf receptor 1 (Fgfr1) are able to undergo or initiate EMT, but cells either fail to migrate away or are unable to maintain the mesenchymal state resulting in their accumulation in the vicinity of the primitive streak (Ciruna et al. 1997; Sun et al. 1999). An absolute requirement for undergoing EMT is down-regulation of junctional proteins and cell adhesion molecules such as E-cadherin (Thiery et al. 2009). Expression of the zinc finger protein Snail, which functions to directly repress E-cadherin, is activated in the primitive streak by Fgf signaling (Ciruna and Rossant 2001). E-cadherin repression is also regulated by the T-box transcription factor Eomesodermin (Eomes). Loss of Eomes results in partial down-regulation of E-cadherin and failure to execute EMT (Arnold et al. 2008).

The last step of primitive streak formation is streak elongation. This process occurs progressively with EMT beginning in the proximal-posterior epiblast and spreading distally/anteriorly. Expansion of the primitive streak requires recruitment of epiblast cells from outside the zone of EMT. It remains unclear how this is accomplished without the disruption of epithelial integrity. Williams et al. (2012) suggest that lateral epiblast cells are recruited to the primitive streak in a passive manner by cellular traction driven by cellular ingression into the streak. In this view, apical constriction of streak cells would pull neighboring cells that are still maintaining a proper cell-cell contact in the epithelium toward the streak. Morphological distortion of the epiblast due to the exit of cells from the epiblast is supposed to be compensated by the high proliferation rates of the epiblast cells in the vicinity of the primitive streak (Wilson and Beddington 1996; Williams et al. 2012).

In addition to cell-cell interactions, the interaction of cells with the extracellular matrix (ECM) are important for cell behavior and, in this case, for cell ingression at the primitive streak, as well as for postingression migration. The ECM regulates many aspects of cell behavior. It provides a checkpoint for growth and developmental signals, serves as the vehicle for morphogenetic gradients, and is the spatial rheostat for intracellular signaling pathways. Consequently, the dynamics of cell-ECM interactions and ECM assembly, remodeling, and degradation are likely to be critical for gastrulation to proceed normally. We know very little regarding the plasma membrane-tethered complexes that link the ECM to the cytoskeleton and intracellular signaling pathways providing the interface between cells and their ECM. The dynamics of these events remain an open question that one might expect will likely gain prominence over the next few years.

\section{FORMATION OF MESODERM AND DEFINITIVE ENDODERM}

The primitive streak is an evolving but stable structure that continually proliferates and generates an ordered series of cell types. After its initial formation at the proximal-posterior epiblast, the primitive streak elongates distally until it reaches the tip of the embryo (E7.5). During this time, the allocation of the distinct lineages of the embryo takes place in an anterior-to-posterior sequence determined by both the time and position of cell ingression at the primitive streak. Thus, cells adopt different fates depending on when and where they leave the primitive streak.

\subsection{Spatiotemporal Regionalization of the Primitive Streak and Its Derivatives}

Fate mapping experiments have revealed that the regionalization of the germ layer progenitors within the epiblast (Lawson et al. 1991; Lawson and Pedersen 1992; Quinlan et al. 1995) and primitive streak (Tam and Beddington 1987; Wilson and Beddington 1996; Kinder et al. 1999, 2001) predicts the body plan of the embryo. Extraembryonic mesoderm, which gives rise to the mesoderm of the visceral yolk sac, amnion, and chorion, is the first lineage to emerge from the primitive streak at its most posterior end. Bmp4, a TGF- $\beta$ signaling molecule expressed in the extraembryonic ectoderm, is involved in patterning this lineage. Subsequently, ingressing cells from middle and anterior streak regions give rise to the cardiac, lateral plate, and paraxial mesoderm. The cell population that emerges, from the anterior primitive streak and early and mid-gastrula organizer (EGO and MGO) regions, gives rise to axial mesendoderm (prechordal plate, notochord, and node), as well as definitive endoderm (Tam et al. 2003).

The duration and level of exposure of a cell to Nodal within the primitive streak likely regulate its fate (Zhou 
et al. 1993; Conlon et al. 1994; Ding et al. 1998). Hypomorphic mutants with moderate levels of Nodal signaling can form some mesoderm and endoderm, but lower levels of Nodal signaling result in a loss of endoderm, but not mesoderm (Lowe et al. 2001; Vincent et al. 2003). In contrast, elevated Nodal signaling caused by loss of the repressor DRAP1 results in an expanded primitive streak and production of excess mesoderm (Iratni et al. 2002).

Recent genetic fate mapping experiments challenge the prevailing view that progenitors of all three germ layers are segregated simultaneously at gastrulation (Tzouanacou et al. 2009). The revised model suggests that, whereas endoderm and surface ectoderm segregate during gastrulation, neural ectoderm and mesoderm share a common progenitor cell population that persists through all stages of axis elongation (Tzouanacou et al. 2009).

\subsection{Widespread Cell Intercalation, Cell Egression, and MET Drive Gut Endoderm Formation}

The gut endoderm is a transient embryonic tissue comprising the progenitors of the epithelial lining of the respiratory and digestive tracts and the precursor cells of visceral organs, such as the lungs, liver, and pancreas. Even though the gut endoderm comes to lie internally within the body, in rodents it arises on the surface of the gastrula-stage embryos. Gut endoderm morphogenesis poses a morphogenetic conundrum to the embryo; cells exit an epithelium with reversed apicobasal polarity from the one in which they will end up. Prospective definitive endoderm cells in the epiblast having executed a program of EMT will eventually insert into the visceral endoderm epithelium positioned on the surface of the embryo, and in doing so must undergo a mesenchymal-to-epithelial transition (MET). Transient or incomplete execution of a program of EMT rapidly followed by MET must therefore occur in definitive endoderm progenitors, or a transient intermediate structure such as multicellular rosettes comprising epithelial cells may form, as has been proposed for node morphogenesis (Yamanaka et al. 2007).

Fate mapping experiments have provided a conceptual reconstruction of the cellular movements involved in gut endoderm formation in the mouse embryo (Lawson et al. 1986; Lawson and Pedersen 1987; Tam and Beddington 1987; Tam et al. 2007; Franklin et al. 2008). Descendants of epiblast cells emerging from the vicinity of the anterior primitive streak, EGO and MGO, end up on the surface of the embryo, often in the area of the definitive endoderm. Fate mapping as well as imaging studies have suggested that definitive endoderm cells may already be specified within the anterior primitive streak and identified by their elevated expression of Foxa2 and reduced expression of Brachyury
(Burtscher and Lickert 2009). The cells polarize as they insert into the surface of the embryo, presumably as they are executing an MET (Burtscher and Lickert 2009; Van Campenhout et al. 2011).

Live imaging studies have also refined our understanding of the cell behaviors driving gut endoderm morphogenesis by showing that embryonic visceral endoderm cells are rapidly dispersed by the egression of definitive endoderm cells, but not displaced en masse as originally believed (Kwon et al. 2008; Kwon and Hadjantonakis 2009; Viotti et al. 2011). In this way, morphogenesis of the gut endoderm is driven by a novel multifocal intercalation mechanism, in which cells committed to a definitive endoderm fate egress between embryonic visceral endoderm (emVE) cells (Fig. 5).

Several transcription factors and signaling pathways, many of them evolutionarily conserved, have been shown to be required for definitive endoderm formation including members of the Forkhead, T-box, HMG-box, Mix/Bix homeobox, and GATA families, as well as TGF- $\beta$ and WNT signaling components (Tam et al. 2003; Zorn and Wells 2009).

Ultrastructural examination of cells within the wings of mesoderm have suggested that the cells adjacent to the emVE are more closely apposed to the basement membrane and more tightly packed than their counterparts that lie closer to the epiblast (Spiegelman and Bennett 1974; Tam and Meier 1982; Lawson et al. 1986), perhaps hinting at an intrinsic heterogeneity within the mesoderm, and/or a subpopulation of cells that may not have undergone a complete program of EMT and are fated as definitive endoderm. These cells would be primed to intercalate into the visceral endoderm epithelium on the surface of the embryo by virtue of both their position and polarization. The notion that cells within the lateral extremities of the wings of mesoderm may be primed to adopt a definitive endoderm fate is supported by their expression of the transcription factors Foxa2 and Sox17 just before, as well as during, egression into the embryonic visceral endoderm (Burtscher and Lickert 2009; Burtscher et al. 2012; Viotti et al. 2012).

\subsection{A Change of State (Not Fate) for Visceral Endoderm at the Onset of Gastrulation}

Analysis of the expression as well as the localization of pan-visceral endoderm markers including $H n f 4 \alpha, A p o C 2$, Transthyretin, and Alphafetoprotein has revealed their gradual down-regulation in emVE cells coincident with the onset of gastrulation (Kwon et al. 2008; Kwon and Hadjantonakis 2009; Viotti et al. 2011). Furthermore, emVE cells cease to show many of the classical morphological traits 
observed in visceral endoderm cells, such as cuboidal shape or extensive vacuolation. This suggests that even though emVE cells are not displaced to extraembryonic regions, they lose aspects of their visceral endoderm identity before widespread intercalation. Moreover, after intercalation is completed, cells of the gut endoderm irrespective of their origin, be it visceral endoderm or epiblast-derived definitive endoderm, express the pan-endodermal marker Sox17 (Viotti et al. 2012). This suggests that consequent to their loss of a visceral endoderm identity, emVE cells acquire an identity resembling their epiblast-derived definitive endoderm neighbors.

Embryonic visceral endoderm (emVE) descendants have been identified in the gut tube at mid-gestation stages (Kwon et al. 2008; Viotti et al. 2012). An intriguing possibility is that these cells persist in the fetus to eventually become incorporated into endoderm derivatives of the adult, a question that requires further investigation. If this is the case, it will be imperative to determine if they are distinguishable from epiblast-derived endoderm tissues under normal or pathological conditions.

\section{PERSPECTIVES AND CONCLUDING REMARKS}

The past two decades have provided a fascinating and unexpected view of the events of embryonic development following implantation of the blastocyst into the uterus. Even so, the fundamental question of how genetic information is mechanistically translated into the threedimensional (3D) organization of the basic body plan remains. We know very little regarding how the tissues of the early mouse embryo generate and maintain their size and shape, and how mechanical constraints and cellular dynamics may affect early morphogenesis. Hence, it is necessary to define the physical forces at work and to understand how they integrate into the molecular networks that are being built from the analysis of mutants. To this end, mathematics and physics concepts will need to be integrated into future data analyses, with modeling of the holistic system activity providing an additional means to generate experimentally testable hypotheses.

\subsection{Image Is Everything}

The next two decades of research will undoubtedly exploit imaging combined with genetic, cellular, or embryological manipulations. To date, even the best cutting-edge live imaging studies have focused on investigating individual populations of cells and drawing conclusions about their behavior in the absence of information on their neighbors. This is a major confounding factor for the interpretation of experimental findings, because it is abundantly clear from previous studies of early postimplantation development that reciprocal interactions between cell populations are crucial in driving morphogenesis.

We can expect that imaging-based methods will be used to report gene activity, protein function, cell behavior, and physical forces. An exciting possibility is the use of optogenetics to control cell function in vivo using light (Zhang et al. 2011; Madisen et al. 2012). By providing descriptors of cellular morphology, the cytoskeleton and signaling activity, live imaging will be used to interrogate cell behaviors across the scales of morphogenesis.

In the same way that molecular and genetic analyses have reinvigorated our understanding of the morphogenesis of the early mouse embryo over the past two decades, recent developments in imaging and specifically the quantitative analysis of biological processes using imagebased assays will, over the next two decades, likely lead to another watershed in our understanding of early mouse development.

\section{ACKNOWLEDGMENTS}

We apologize to the many authors whose work we failed to discuss because of space constraints. We thank the editors, as well as Anna Ferrer-Vaquer, Sonja Nowotschin, and Aitana Perea-Gomez, for critical reading of this review and suggestions for improvement. Work in our laboratories is supported by National Institutes of Health grants GM87130 and GM94874 (to J.A.R.-P.) and HD052115 and DK084391 (to A.-K.H.).

\section{REFERENCES}

* Reference is also in this collection.

Ang S-L, Constam DB. 2004. A gene network establishing polarity in the early mouse embryo. Dev Biol 15: 555-561.

Arnold SJ, Robertson EJ. 2009. Making a commitment: Cell lineage allocation and axis patterning in the early mouse embryo. Nat Rev Mol Cell Biol 10: 91-103.

Arnold SJ, Huang GJ, Cheung AF, Era T, Nishikawa S, Bikoff EK, Molnar Z, Robertson EJ, Groszer M. 2008. The T-box transcription factor Eomes/Tbr2 regulates neurogenesis in the cortical subventricular zone. Genes Dev 22: 2479-2484.

Arnold SJ, Sugnaseelan J, Groszer M, Srinivas S, Robertson EJ. 2009. Generation and analysis of a mouse line harboring GFP in the Eomes/Tbr2 locus. Genesis 47: 775-781.

Barrow JR, Howell WD, Rule M, Hayashi S, Thomas KR, Capecchi MR, McMahon AP. 2007. Wnt3 signaling in the epiblast is required for proper orientation of the anteroposterior axis. Dev Biol 312: $312-320$.

Beck S, Le Good JA, Guzman M, Ben Haim N, Roy K, Beermann F, Constam DB. 2002. Extraembryonic proteases regulate Nodal signalling during gastrulation. Nat Cell Biol 4: 981-985.

Ben-Haim N, Lu C, Guzman-Ayala M, Pescatore L, Mesnard D, Bischofberger M, Naef F, Robertson EJ, Constam DB. 2006. The nodal precursor acting via activin receptors induces mesoderm by maintaining a source of its convertases and BMP4. Dev Cell 11: 313-323. 
Bielinska M, Narita N, Wilson DB. 1999. Distinct roles for visceral endoderm during embryonic mouse development. Int J Dev Biol 43: $183-205$.

Brown NH. 2011. Extracellular matrix in development: Insights from mechanisms conserved between invertebrates and vertebrates. Cold Spring Harb Perspect Biol 3: a005082.

Burtscher I, Lickert H. 2009. Foxa2 regulates polarity and epithelialization in the endoderm germ layer of the mouse embryo. Development 136: $1029-1038$.

Burtscher I, Barkey W, Schwarzfischer M, Theis FJ, Lickert H. 2012. The Sox17-mCherry fusion mouse line allows visualization of endoderm and vascular endothelial development. Genesis 50: 496-505.

Chazaud C, Rossant J. 2006. Disruption of early proximodistal patterning and AVE formation in Apc mutants. Development 133: 3379-3387.

Chazaud C, Yamanaka Y, Pawson T, Rossant J. 2006. Early lineage segregation between epiblast and primitive endoderm in mouse blastocysts through the Grb2-MAPK pathway. Dev Cell 10: 615-624.

Ciruna B, Rossant J. 2001. FGF signaling regulates mesoderm cell fate specification and morphogenetic movement at the primitive streak. Dev Cell 1: 37-49.

Ciruna BG, Schwartz L, Harpal K, Yamaguchi TP, Rossant J. 1997. Chimeric analysis of fibroblast growth factor receptor-1 (Fgfr1) function: A role for FGFR1 in morphogenetic movement through the primitive streak. Development 124: 2829-2841.

Conlon FL, Lyons KM, Takaesu N, Barth KS, Kispert A, Herrmann B, Robertson EJ. 1994. A primary requirement for nodal in the formation and maintenance of the primitive streak in the mouse. Development 120: $1919-1928$.

Copp AJ. 1979. Interaction between inner cell mass and trophectoderm of the mouse blastocyst. II. The fate of the polar trophectoderm. $J$ Embryol Exp Morphol 51: 109-120.

Coucouvanis E, Martin GR. 1995. Signals for death and survival: A twostep mechanism for cavitation in the vertebrate embryo. Cell 83: 279-287.

Coucouvanis E, Martin GR. 1999. BMP signaling plays a role in visceral endoderm differentiation and cavitation in the early mouse embryo. Development 126: 535-546.

Crompton LA, Du Roure C, Rodriguez TA. 2007. Early embryonic expression patterns of the mouse Flamingo and Prickle orthologues. Dev Dyn 236: 3137-3143.

Davidson AJ, Insall RH. 2011. Actin-based motility: WAVE regulatory complex structure reopens old SCARs. Curr Biol 21: R66-R68.

de Sousa Lopes SM, Roelen BA, Monteiro RM, Emmens R, Lin HY, Li E, Lawson KA, Mummery CL. 2004. BMP signaling mediated by ALK2 in the visceral endoderm is necessary for the generation of primordial germ cells in the mouse embryo. Genes Dev 18: 1838-1849.

Ding J, Yang L, Yan YT, Chen A, Desai N, Wynshaw-Boris A, Shen MM. 1998. Cripto is required for correct orientation of the anterior-posterior axis in the mouse embryo. Nature 395: 702-707.

Donnison M, Beaton A, Davey HW, Broadhurst R, L'Huillier P, Pfeffer PL. 2005. Loss of the extraembryonic ectoderm in Elf5 mutants leads to defects in embryonic patterning. Development 132: 2299-2308.

Escalante-Alcalde D, Hernandez L, Le Stunff H, Maeda R, Lee HS Jr, Gang C, Sciorra VA, Daar I, Spiegel S, Morris AJ, et al. 2003. The lipid phosphatase LPP3 regulates extra-embryonic vasculogenesis and axis patterning. Development 130: 4623-4637.

Franklin V, Khoo PL, Bildsoe H, Wong N, Lewis S, Tam PP. 2008. Regionalisation of the endoderm progenitors and morphogenesis of the gut portals of the mouse embryo. Mech Dev 125: 587-600.

Gardel ML, Schneider IC, Aratyn-Schaus Y, Waterman CM. 2009. Mechanical integration of actin and adhesion dynamics in cell migration. Annu Rev Cell Dev Biol 26: 315-333.

Georgiades P, Rossant J. 2006. Ets2 is necessary in trophoblast for normal embryonic anteroposterior axis development. Development 133: $1059-1068$.

Guo Q, Li JY. 2007. Distinct functions of the major Fgf8 spliceform, Fgf8b, before and during mouse gastrulation. Development 134: 2251-2260.
Huelsken J, Vogel R, Brinkmann V, Erdmann B, Birchmeier C, Birchmeier W. 2000. Requirement for $\beta$-catenin in anterior-posterior axis formation in mice. J Cell Biol 148: 567-78.

Iratni R, Yan YT, Chen C, Ding J, Zhang Y, Price SM, Reinberg D, Shen MM. 2002. Inhibition of excess nodal signaling during mouse gastrulation by the transcriptional corepressor DRAP1. Science 298: 19961999.

Kanai-Azuma M, Kanai Y, Gad JM, Tajima Y, Taya C, Kurohmaru M, Sanai Y, Yonekawa H, Yazaki K, Tam PP, et al. 2002. Depletion of definitive gut endoderm in Sox17-null mutant mice. Development 129: $2367-2379$.

Kawano Y, Kypta R. 2003. Secreted antagonists of the Wnt signalling pathway. J Cell Sci 116: 2627-2634.

Kemp CR, Willems E, Wawrzak D, Hendrickx M, Agbor Agbor T, Leyns L. 2007. Expression of Frizzled5, Frizzled7, and Frizzled10 during early mouse development and interactions with canonical Wnt signaling. Dev Dyn 236: 2011-2019.

Kimura C, Yoshinaga K, Tian E, Suzuki M, Aizawa S, Matsuo I. 2000. Visceral endoderm mediates forebrain development by suppressing posteriorizing signals. Dev Biol 225: 304-321.

Kimura-Yoshida C, Nakano H, Okamura D, Nakao K, Yonemura S, Belo JA, Aizawa S, Matsui Y, Matsuo I. 2005. Canonical Wnt signaling and its antagonist regulate anterior-posterior axis polarization by guiding cell migration in mouse visceral endoderm. Dev Cell 9: 639-650.

Kinder SJ, Tsang TE, Quinlan GA, Hadjantonakis AK, Nagy A, Tam PP. 1999. The orderly allocation of mesodermal cells to the extraembryonic structures and the anteroposterior axis during gastrulation of the mouse embryo. Development 126: 4691-4701.

Kinder SJ, Tsang TE, Wakamiya M, Sasaki H, Behringer RR, Nagy A, Tam PP. 2001. The organizer of the mouse gastrula is composed of a dynamic population of progenitor cells for the axial mesoderm. Development 128: 3623-3634.

Kwon GS, Hadjantonakis AK. 2009. Transthyretin mouse transgenes direct RFP expression or Cre-mediated recombination throughout the visceral endoderm. Genesis 47: 447-455.

Kwon GS, Viotti M, Hadjantonakis AK. 2008. The endoderm of the mouse embryo arises by dynamic widespread intercalation of embryonic and extraembryonic lineages. Dev Cell 15: 509-520.

Lawson KA, Pedersen RA. 1987. Cell fate, morphogenetic movement and population kinetics of embryonic endoderm at the time of germ layer formation in the mouse. Development 101: 627-652.

Lawson KA, Pedersen RA. 1992. Clonal analysis of cell fate during gastrulation and early neurulation in the mouse. Ciba Found Symp 165: $3-21$.

Lawson KA, Meneses JJ, Pedersen RA. 1986. Cell fate and cell lineage in the endoderm of the presomite mouse embryo, studied with an intracellular tracer. Dev Biol 115: 325-339.

Lawson KA, Meneses JJ, Pedersen RA. 1991. Clonal analysis of epiblast fate during germ layer formation in the mouse embryo. Development 113: 891-911.

Lawson KA, Dunn NR, Roelen BA, Zeinstra LM, Davis AM, Wright CV, Korving JP, Hogan BL. 1999. Bmp4 is required for the generation of primordial germ cells in the mouse embryo. Genes Dev 13: 424436.

Lin TP, Labosky PA, Grabel LB, Kozak CA, Pitman JL, Kleeman J, MacLeod CL. 1994. The Pem homeobox gene is X-linked and exclusively expressed in extraembryonic tissues during early murine development. Dev Biol 166: 170-179.

Liu P, Wakamiya M, Shea MJ, Albrecht U, Behringer RR, Bradley A. 1999. Requirement for Wnt3 in vertebrate axis formation. Nat Genet 22: 361-365.

Lowe LA, Yamada S, Kuehn MR. 2001. Genetic dissection of nodal function in patterning the mouse embryo. Development 128: 18311843. 
Lu CC, Robertson EJ. 2004. Multiple roles for Nodal in the epiblast of the mouse embryo in the establishment of anterior-posterior patterning. Dev Biol 273: 149-159.

Madabhushi M, Lacy E. 2011. Anterior visceral endoderm directs ventral morphogenesis and placement of head and heart via BMP2 expression. Dev Cell 21: 907-919.

Madisen L, Mao T, Koch H, Zhuo JM, Berenyi A, Fujisawa S, Hsu YW, Garcia AJ III, Gu X, Zanella S, et al. 2012. A toolbox of Cre-dependent optogenetic transgenic mice for light-induced activation and silencing. Nat Neurosci 15: 793-802.

Maretto S, Cordenonsi M, Dupont S, Braghetta P, Broccoli V, Hassan AB, Volpin D, Bressan GM, Piccolo S. 2003. Mapping Wnt $/ \beta$-catenin signaling during mouse development and in colorectal tumors. Proc Natl Acad Sci 100: 3299-3304.

Mattila PK, Lappalainen P. 2008. Filopodia: Molecular architecture and cellular functions. Nat Rev Mol Cell Biol 9: 446-454.

Mesnard D, Constam DB. 2010. Imaging proprotein convertase activities and their regulation in the implanting mouse blastocyst. J Cell Biol 191: $129-139$.

Mesnard D, Filipe M, Belo JA, Zernicka-Goetz M. 2004. The anteriorposterior axis emerges respecting the morphology of the mouse embryo that changes and aligns with the uterus before gastrulation. Curr Biol 14: 184-196.

Migeotte I, Omelchenko T, Hall A, Anderson KV. 2010. Rac1-dependent collective cell migration is required for specification of the anteriorposterior body axis of the mouse. PLoS Biol 8: e1000442.

Mohamed OA, Clarke HJ, Dufort D. 2004. $\beta$-Catenin signaling marks the prospective site of primitive streak formation in the mouse embryo. Dev Dyn 231: 416-424.

Nakaya Y, Sukowati EW, Wu Y, Sheng G. 2008. RhoA and microtubule dynamics control cell-basement membrane interaction in EMT during gastrulation. Nat Cell Biol 10: 765-775.

Ohinata Y, Ohta H, Shigeta M, Yamanaka K, Wakayama T, Saitou M. 2009. A signaling principle for the specification of the germ cell lineage in mice. Cell 137: 571-584.

Pearce JJ, Evans MJ. 1999. Mml, a mouse Mix-like gene expressed in the primitive streak. Mech Dev 87: 189-192.

Perea-Gomez A, Lawson KA, Rhinn M, Zakin L, Brulet P, Mazan S, Ang SL. 2001. Otx2 is required for visceral endoderm movement and for the restriction of posterior signals in the epiblast of the mouse embryo. Development 128: 753-765.

Perea-Gomez A, Vella FD, Shawlot W, Oulad-Abdelghani M, Chazaud C, Meno C, Pfister V, Chen L, Robertson E, Hamada H, et al. 2002. Nodal antagonists in the anterior visceral endoderm prevent the formation of multiple primitive streaks. Dev Cell 3: 745-756.

Perea-Gomez A, Camus A, Moreau A, Grieve K, Moneron G, Dubois A, Cibert C, Collignon J. 2004. Initiation of gastrulation in the mouse embryo is preceded by an apparent shift in the orientation of the anterior-posterior axis. Curr Biol 14: 197-207.

Perea-Gomez A, Meilhac SM, Piotrowska-Nitsche K, Gray D, Collignon J, Zernicka-Goetz M. 2007. Regionalization of the mouse visceral endoderm as the blastocyst transforms into the egg cylinder. BMC Dev Biol 7: 96.

Pereira PN, Dobreva MP, Graham L, Huylebroeck D, Lawson KA, Zwijsen AN. 2011. Amnion formation in the mouse embryo: The single amniochorionic fold model. BMC Dev Biol 11: 48.

Pfister S, Steiner KA, Tam PP. 2007. Gene expression pattern and progression of embryogenesis in the immediate post-implantation period of mouse development. Gene Expr Patterns 7: 558-573.

Quinlan GA, Williams EA, Tan SS, Tam PP. 1995. Neuroectodermal fate of epiblast cells in the distal region of the mouse egg cylinder: Implication for body plan organization during early embryogenesis. Development 121: 87-98.

Raftopoulou M, Hall A. 2004. Cell migration: Rho GTPases lead the way. Dev Biol 265: 23-32.
Rakeman AS, Anderson KV. 2006. Axis specification and morphogenesis in the mouse embryo require Nap1, a regulator of WAVE-mediated actin branching. Development 133: 3075-3083.

Richardson L, Torres-Padilla ME, Zernicka-Goetz M. 2006. Regionalised signalling within the extraembryonic ectoderm regulates anterior visceral endoderm positioning in the mouse embryo. Mech Dev 123: $288-296$.

Rivera-Perez JA, Magnuson T. 2005. Primitive streak formation in mice is preceded by localized activation of Brachyury and Wnt3. Dev Biol 288: $363-71$.

Rivera-Perez JA, Mager J, Magnuson T. 2003. Dynamic morphogenetic events characterize the mouse visceral endoderm. Dev Biol 261: $470-487$.

Robb L, Hartley L, Begley CG, Brodnicki TC, Copeland NG, Gilbert DJ, Jenkins NA, Elefanty AG. 2000. Cloning, expression analysis, and chromosomal localization of murine and human homologues of a Xenopus mix gene. Dev Dyn 219: 497-504.

Rodriguez TA, Casey ES, Harland RM, Smith JC, Beddington RS. 2001. Distinct enhancer elements control Hex expression during gastrulation and early organogenesis. Dev Biol 234: 304-316.

Rodriguez TA, Srinivas S, Clements MP, Smith JC, Beddington RS. 2005. Induction and migration of the anterior visceral endoderm is regulated by the extra-embryonic ectoderm. Development 132: 2513-2520.

Rosenquist TA, Martin GR. 1995. Visceral endoderm-1 (VE-1): An antigen marker that distinguishes anterior from posterior embryonic visceral endoderm in the early post-implantation mouse embryo. Mech Dev 49: 117-121.

Salgueiro AM, Filipe M, Belo JA. 2006. N-acetylgalactosamine 4-sulfate 6-O-sulfotransferase expression during early mouse embryonic development. Int J Dev Biol 50: 705-708.

Snell GD, Stevens LC. 1966. Early embryology. In Biology of the laboratory mouse (ed. Green EL), pp. 1-54. McGraw-Hill, New York.

Snow MHL. 1977. Gastrulation in the mouse: Growth and regionalization of the epiblast. J. Embryol Exp Morph 42: 293-303.

Spiegelman M, Bennett D. 1974. Fine structural study of cell migration in the early mesoderm of normal and mutant mouse embryos (T-locus: t-9/t-9). J Embryol Exp Morphol 32: 723-728.

Srinivas S, Rodriguez T, Clements M, Smith JC, Beddington RS. 2004. Active cell migration drives the unilateral movements of the anterior visceral endoderm. Development 131: 1157-1164.

* Stephenson RO, Rossant J, Tam PPL. 2012. Intercellular interactions, position, and polarity in establishing blastocyst cell lineages and embryonic axes. Cold Spring Harb Perspect Biol 4: a008235.

Stuckey DW, Clements M, Di-Gregorio A, Senner CE, Le Tissier P, Srinivas S, Rodriguez TA. 2011. Coordination of cell proliferation and anterior-posterior axis establishment in the mouse embryo. Development 138: $1521-1530$.

Sun X, Meyers EN, Lewandoski M, Martin GR. 1999. Targeted disruption of Fgf8 causes failure of cell migration in the gastrulating mouse embryo. Genes Dev 13: 1834-1846.

Takaoka K, Yamamoto M, Hamada H. 2011. Origin and role of distal visceral endoderm, a group of cells that determines anterior-posterior polarity of the mouse embryo. Nat Cell Biol 13: 743-752.

Tam PP, Beddington RS. 1987. The formation of mesodermal tissues in the mouse embryo during gastrulation and early organogenesis. Development 99: 109-126.

Tam PP, Meier S. 1982. The establishment of a somitomeric pattern in the mesoderm of the gastrulating mouse embryo. Am J Anat 164: 209225.

Tam PP, Kanai-Azuma M, Kanai Y. 2003. Early endoderm development in vertebrates: Lineage differentiation and morphogenetic function. Curr Opin Genet Dev 13: 393-400.

Tam PP, Khoo PL, Lewis SL, Bildsoe H, Wong N, Tsang TE, Gad JM, Robb L. 2007. Sequential allocation and global pattern of movement of the definitive endoderm in the mouse embryo during gastrulation. Development 134: 251-260. 
Thiery JP, Acloque H, Huang RY, Nieto MA. 2009. Epithelial-mesenchymal transitions in development and disease. Cell 139: 871-890.

Thomas P, Beddington R. 1996. Anterior primitive endoderm may be responsible for patterning the anterior neural plate in the mouse embryo. Curr Biol 6: 1487-1496.

Tortelote GG, Hernandez-Hernandez M, Quaresma A, Nickerson J, Imbalzano AN, Rivera-Perez JA. 2013. Wnt3 function in the epiblast is required for the maintenance but not the initiation of gastrulation in mice. Dev Biol 374: 164-173.

Trichas G, Joyce B, Crompton LA, Wilkins V, Clements M, Tada M, Rodriguez TA, Srinivas S. 2011. Nodal dependent differential localisation of dishevelled-2 demarcates regions of differing cell behaviour in the visceral endoderm. PLoS Biol 9: e1001019.

Trichas G, Smith AM, White N, Wilkins V, Watanabe T, Moore A, Joyce B, Sugnaseelan J, Rodriguez TA, Kay D, et al. 2012. Multi-cellular rosettes in the mouse visceral endoderm facilitate the ordered migration of anterior visceral endoderm cells. PLoS Biol 10: e1001256.

Tzouanacou E, Wegener A, Wymeersch FJ, Wilson V, Nicolas JF. 2009. Redefining the progression of lineage segregations during mammalian embryogenesis by clonal analysis. Dev Cell 17: 365-376.

Van Campenhout CA, Eitelhuber A, Gloeckner CJ, Giallonardo P, Gegg M, Oller H, Grant SG, Krappmann D, Ueffing M, Lickert H. 2011. Dlg3 trafficking and apical tight junction formation is regulated by nedd4 and nedd4-2 e3 ubiquitin ligases. Dev Cell 21: 479-491.

Vincent SD, Dunn NR, Hayashi S, Norris DP, Robertson EJ. 2003. Cell fate decisions within the mouse organizer are governed by graded Nodal signals. Genes Dev 17: 1646-1662.

Viotti M, Nowotschin S, Hadjantonakis AK. 2011. Afp::mCherry, a red fluorescent transgenic reporter of the mouse visceral endoderm. Genesis 49: $124-133$.

Viotti M, Niu L, Shi SH, Hadjantonakis AK. 2012. Role of the gut endoderm in relaying left-right patterning in mice. PLoS Biol 10: e1001276.

Voiculescu O, Bertocchini F, Wolpert L, Keller RE, Stern CD. 2007. The amniote primitive streak is defined by epithelial cell intercalation before gastrulation. Nature 449: 1049-1052.
Weber RJ, Pedersen RA, Wianny F, Evans MJ, Zernicka-Goetz M. 1999. Polarity of the mouse embryo is anticipated before implantation. Development 126: 5591-5598.

Williams M, Burdsal C, Periasamy A, Lewandoski M, Sutherland A. 2012. Mouse primitive streak forms in situ by initiation of epithelial to mesenchymal transition without migration of a cell population. Dev Dyn 241: 270-283.

Wilson V, Beddington RS. 1996. Cell fate and morphogenetic movement in the late mouse primitive streak. Mech Dev 55: 79-89.

Winnier G, Blessing M, Labosky PA, Hogan BL. 1995. Bone morphogenetic protein- 4 is required for mesoderm formation and patterning in the mouse. Genes Dev 9: 2105-2116.

Yamamoto M, Saijoh Y, Perea-Gomez A, Shawlot W, Behringer RR, Ang SL, Hamada H, Meno C. 2004. Nodal antagonists regulate formation of the anteroposterior axis of the mouse embryo. Nature 428: 387-392.

Yamamoto M, Beppu H, Takaoka K, Meno C, Li E, Miyazono K, Hamada H. 2009. Antagonism between Smad1 and Smad2 signaling determines the site of distal visceral endoderm formation in the mouse embryo. J Cell Biol 184: 323-334.

Yamanaka Y, Tamplin OJ, Beckers A, Gossler A, Rossant J. 2007. Live imaging and genetic analysis of mouse notochord formation reveals regional morphogenetic mechanisms. Dev Cell 13: 884-896.

Zakin L, Reversade B, Virlon B, Rusniok C, Glaser P, Elalouf JM, Brulet P. 2000. Gene expression profiles in normal and Otx $2^{-/-}$early gastrulating mouse embryos. Proc Natl Acad Sci 97: 14388-14393.

Zhang F, Vierock J, Yizhar O, Fenno LE, Tsunoda S, Kianianmomeni A, Prigge M, Berndt A, Cushman J, Polle J, et al. 2011. The microbial opsin family of optogenetic tools. Cell 147: 1446-1457.

Zhou X, Sasaki H, Lowe L, Hogan BL, Kuehn MR. 1993. Nodal is a novel TGF- $\beta$-like gene expressed in the mouse node during gastrulation. Nature 361: 543-547.

Zorn AM, Wells JM. 2009. Vertebrate endoderm development and organ formation. Annu Rev Cell Dev Biol 25: 221-251. 


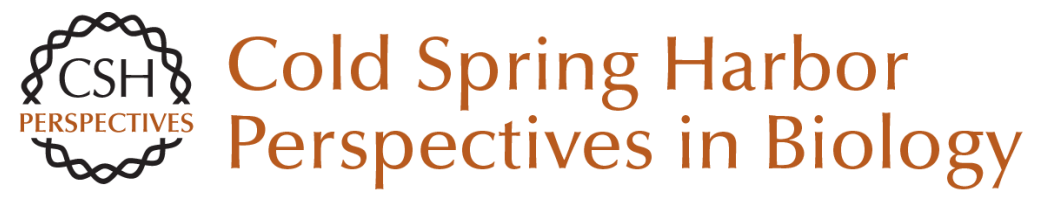

\section{The Dynamics of Morphogenesis in the Early Mouse Embryo}

Jaime A. Rivera-Pérez and Anna-Katerina Hadjantonakis

Cold Spring Harb Perspect Biol 2015; doi: 10.1101/cshperspect.a015867 originally published online June 26, 2014

\section{Subject Collection Mammalian Development}

The Dynamics of Morphogenesis in the Early Mouse Embryo

Jaime A. Rivera-Pérez and Anna-Katerina Hadjantonakis

microRNAs as Developmental Regulators Kathryn N. Ivey and Deepak Srivastava

Development of the Endochondral Skeleton Fanxin Long and David M. Ornitz

\section{Adipogenesis}

Kelesha Sarjeant and Jacqueline M. Stephens

Molecular Mechanisms of Inner Ear Development Doris K. Wu and Matthew W. Kelley

Polarity in Mammalian Epithelial Morphogenesis Julie Roignot, Xiao Peng and Keith Mostov

Eye Development and Retinogenesis

Whitney Heavner and Larysa Pevny

Primordial Germ Cells in Mice

Mitinori Saitou and Masashi Yamaji
Cell Division Modes and Cleavage Planes of

Neural Progenitors during Mammalian Cortical

Development

Fumio Matsuzaki and Atsunori Shitamukai

Blood and Lymphatic Vessel Formation

Victoria L. Bautch and Kathleen M. Caron

Transcriptional Networks in Liver and Intestinal

Development

Karyn L. Sheaffer and Klaus H. Kaestner

Pluripotency in the Embryo and in Culture Jennifer Nichols and Austin Smith

Signaling and Transcriptional Networks in Heart Development and Regeneration

Benoit G. Bruneau

Signals and Switches in Mammalian Neural Crest

Cell Differentiation

Shachi Bhatt, Raul Diaz and Paul A. Trainor

Hematopoiesis

Michael A. Rieger and Timm Schroeder

Intercellular Interactions, Position, and Polarity in

Establishing Blastocyst Cell Lineages and

Embryonic Axes

Robert O. Stephenson, Janet Rossant and Patrick P.L. Tam

For additional articles in this collection, see http://cshperspectives.cshlp.org/cgi/collection/

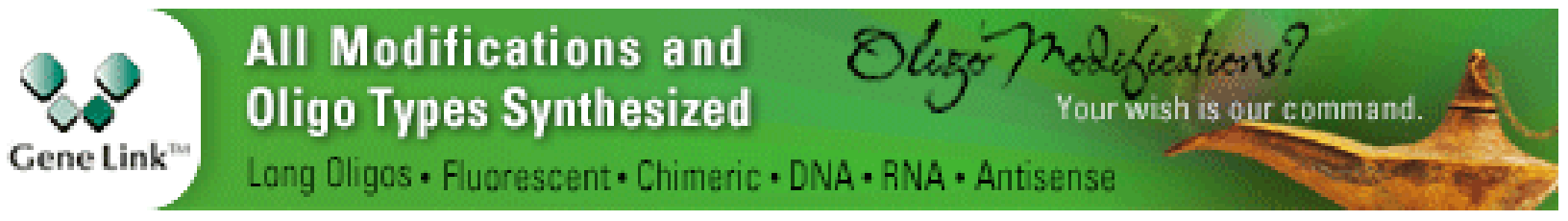

Copyright @ 2015 Cold Spring Harbor Laboratory Press; all rights reserved 